\title{
Contação de histórias infantis: promovendo a imaginação e o lúdico
}

Márcia Onísia da Silvaํㅡ. Márcia Maria Aparecida Severino Garcia², Rita de Cássia da Silva ${ }^{3}$

RESUMO: Neste artigo apresenta-se as ações realizadas em dois projetos de extensão de contação de histórias vinculados a Departamento de Economia Doméstica da Universidade Federal de Viçosa, apontando diferentes pontos de vista sobre a importância da arte de se contar historias e a necessidade de resgatar as cantigas de roda, realizando um trabalho integrado com as escolas e com a comunidade, por meio do trabalho extensionista, no qual atende-se crianças e adultos de diferentes faixas etárias.

Palavras chave: Cantigas de roda, histórias infantis, lúdico e resgate da tradição oral.

Áreas temáticas: Cultura e comunicação. 


\section{Storytelling children: promoting imagination and playful- ness}

ABSTRACT: This article aims to analyze different views about the art of telling stories and the need to rescue the "cantigas de roda" from ancient times up to contemporary times. This work relies on the activities experienced in the extension project linked to the Departamento de Economia Doméstica da Universidade Federal de Viçosa titled "imagination and playfulness: the storytelling children's stories".

Keywords: Children's stories, rescue of oral tradicion , playful, cantigas de roda.

Thematic areas: Culture and communication.

\section{Cuentacuentos infantil: la promoción de la imaginación y de la alegría}

RESUMEN: Este artículo pretende analizar diferentes puntos de vista sobre el arte de contar historias y la necesidad de rescatar la cantigas de roda desde la antigüedad hasta la época contemporánea. Este trabajo se basa en las experiencias vividas en el proyecto de extensión, relacionado con el Departamento de Economía Domestica de la Universidade Federal de Viçosa, titulada "la imaginación y el juego: la narración de cuentos para niños".

Palabras clave: Cuentos infantiles, rescate de la tradicion orales, juguetón, cantigas de roda.

Áreas temáticas: Cultura y comunicación. 


\section{INTRODUÇÃO}

As primeiras experiências do ser humano com as atividades de leitura costumam ocorrer das mais diversas formas, segundo fatores como as condições econômicas e sociais de acesso aos livros e demais impressos que circulam em sociedade (SILVA \& MARTINS, 2010). Muitos autores em suas discussões acerca da literatura infantil suscitam a importância desta nas instituições de atendimento a crianças de 0 a 6 anos e na vida da criança nos diferentes espaços sociais em que esta se insere.

Para Souza (2011), a formação dos professores e as questões teórico-metodológicas que envolvem a seleção de livros para crianças, bem como o uso dos mesmos, são pontos de discussão para início de um bom trabalho de contação de histórias. Parte das escolas não possui acervo suficiente e, quando possui, nem sempre estão em bom estado de conservação ou são adequados à faixa etária. Em muitos casos, os livros são guardados em estantes altas onde as crianças não têm acesso a eles ou ficam nas bibliotecas, espaço nem sempre utilizado com a freqüência apropriada. As crianças ouvem histórias somente para passar o tempo, sendo esta uma atividade que não faz parte da rotina. Por outro lado, alguns fatores podem ser um entrave para que as famílias não incorporem dentre suas atividades, a prática de contar histórias para as crianças. Destacam-se entre os fatores o analfabetismo, a desinformação, o desinteresse, a vida corrida, a falta de recursos (livros ainda são objetos de alto valor), facilidade de acesso às mídias televisivas.

Diante desse cenário, é necessário problematizar a relação dos adultos (professores e pais) com as crianças e com a literatura infantil. A forma como educadores da infância agem e o que pensam sobre a seleção e a narração das histórias infantis determina e reflete o conceito que têm de criança. Citando um exemplo, há certas religiões que tentam privar as crianças dos contos de fada. Será que o contato da criança com estes contos pode afetar suas crenças e valores? Privá-la de ouvi-los é a solução para que seja educada dentro dos valores religiosos adotados pela família? Ela será corrompida pelas ideias que o conto traz? Neste contexto, as tentativas de inovar as ações concretas na prática de contar histórias enfrentam barreiras, muitas destas invisíveis, outras visíveis que, conforme Cunha (2003), são vivas e atuantes e esbarram nas concepções de pais, supervisores, na organização do espaço físico, nos horários, na forma de organização da rotina e na visão que se tem da história como passatempo ou como atividade importante para o desenvolvimento da criança. 
Constatou-se, por meio de estágios e de desenvolvimento de projetos junto às escolas de Viçosa, que esta situação também ocorre nas instituições de ensino desta região. Em função desta constatação, empreenderam-se vários estudos para verificar in loco que ações poderiam ser realizadas no sentido de amenizar ou mesmo modificar esta situação. Em contato com os professores de educação infantil e ensino fundamental, percebeu-se o interesse deles pela literatura infantil, porém, muitos não a incluíam em seu planejamento, apontando limitações como falta de livros de história nas creches e/ou escolas, falta de tempo na rotina escolar, desconhecimento de técnicas e de recursos, e até a ideia de que seria uma atividade extra e que interferiria nas atividades curriculares, entre outras.

Do estudo realizado, surgiram os projetos "A imaginação e o lúdico: a contação de Histórias Infantis", e "Conta de novo? Produzindo histórias infantis e dramatização por diferentes técnicas". O primeiro está em atividade desde o ano de 2008, e o segundo desde 2012, ambos em parceria com editoras, livrarias e Secretaria de Cultura da Prefeitura Municipal de Viçosa, que colaboraram com a logística de realização dos projetos. Os projetos advêm do envolvimento da equipe de professores e técnicos da área de Família e Desenvolvimento Humano do Departamento de Economia Doméstica em cursos de formação de professores que atuam na Educação Infantil, em Viçosa-MG e em outras cidades vizinhas.

A ideia era, inicialmente, trabalhar com oficinas teórico-práticas para esses professores. No entanto, com o tempo, implantou-se a contação de histórias periodicamente em espaços públicos, uma vez que foi verificado que as pessoas (crianças e adultos) que tiveram contato com os projetos se envolveram e interagiram de forma positiva, solicitando à equipe do projeto que tivessem ações nesse sentido.

Esses projetos têm várias vertentes de ação e concretizam-se por meio de atividades voltadas ao público infantil e adulto. Uma destas ações são as contações de histórias na Praça Silviano Brandão e outras praças na Cidade Universitária de Viçosa - MG. Esta atividade ocorre uma vez por mês, sempre aos sábados. A outra ação é o oferecimento de oficinas, onde professores, coordenadores pedagógicos e demais profissionais da educação podem refletir sobre a prática de contação de histórias, a implicação teórica desta atividade na vida e no desenvolvimento da criança e aprendem a utilizar diferentes recursos para contação de histórias. Os livros infantis são ainda muito caros, o que os torna pouco acessíveis para as escolas. Desta forma, nas oficinas, os profissionais aprendem diferentes técnicas para confeccionar histórias, aproveitando materiais que seriam descartados, contribuindo para a preservação do ambiente e a educação ambiental. 
A grande problemática colocada é: como operacionalizar esta atividade no dia-a-dia sem perder o espaço para a imaginação e o lúdico e ainda manter as outras atividades escolares? Desta, desdobram-se outras questões tão importantes, como: nas instituições educacionais, seja na Educação Infantil ou no Ensino Fundamental, quais são as condições oferecidas aos professores para o desenvolvimento de um programa educativo de qualidade? Os professores e as famílias/crianças têm acesso à literatura infantil? Existem bibliotecas ou outros espaços para contar histórias nas creches ou pré-escolas? A leitura e/ou a narração de histórias é uma atividade cotidiana? A população de Viçosa e região tem contato com atividades de contação de histórias?

Nesse sentido, visando responder a essas questões e minimizar os problemas encontrados em relação à literatura infantil, o foco principal desses projetos é a contação de histórias, independente da conotação teórica dada ao termo. O intuito é o de promover momentos de prazer e de ludicidade, de imaginação, criação, levando a criança a questionar valores, princípios embutidos nas histórias a que têm acesso.

Os projetos têm como propósito propiciar momentos lúdicos, constituindo-se em mais uma oportunidade para que os professores possam refletir sobre a sua prática pedagógica e redimensioná-la, exercitando o seu papel de propiciador de encantamentos, por meio da narração de histórias infantis, utilizando-se de diferentes recursos didáticos e oportunizando à criança expansão do seu mundo, apoiando em instrumentos que possibilitem ressignificá-lo.

Nesse contexto, os projetos de contação de histórias têm como objetivo geral contribuir para o fortalecimento, enriquecimento e inovação da prática de contar histórias, utilizando-se de diferentes recursos didáticos confeccionados pelos próprios profissionais, buscando a reutilização de material descartado e levar a imaginação e o lúdico às crianças durante atividades de contação de histórias em diversos espaços. Apesar da proposta inicial visar crianças da educação infantil, no decorrer das atividades, o trabalho acabou se estendendo para crianças maiores, entre 7 e 12 anos, e também adultos.

\section{UMA BREVE REVISÃO EXPLICATIVA}

O homem aprimorou os seus talentos e se especializou nas artes para ganhar a admiração dos seus semelhantes, como afirma Tahan (1966). Usando a arte de contar histórias para ganhar a admiração das pessoas acabou por tornar-se o centro de atenção popular, através do prazer oferecido por meio das histórias. A contação oral 
de histórias na antiguidade era vista como inferior às atividades de escrita, no entanto, as pessoas se reuniam ao redor de fogueiras para narrar lendas e contos, pelas quais disseminavam a cultura e os costumes locais. A história tem sido utilizada pelo homem para veicular verdades, conservando as tradições ou difundindo novas ideias. Mas esta era uma atividade dos simplórios - aqueles que não sabiam ler nem escrever. Com o tempo, descobriu-se que as histórias entretinham, causavam admiração e conquistavam as pessoas, fazendo do contador o centro das atenções (SOUZA, 2011).

Bussato (2003) afirma que há registros antes e depois de Cristo, percebendo-se, desta forma, a importância da oralidade na vida do homem desde os tempos mais remotos até a contemporaneidade. É notável a necessidade e a vontade de comunicação do ser humano, compreendendo-se como fundamental a permanência da contação de histórias. Mesmo que, com o passar dos tempos, os contos sejam modificados recebendo as influências do mundo contemporâneo, devem-se preservar a essência e o poder da palavra em encantar as pessoas.

Meireles (1984) traz uma reflexão importante que nos remete ao passado mais recente, acrescentando ao que é citado por Bussato Para ele, sempre existiu quem contasse histórias, como as professoras de Educação Infantil, as amas de leite e as avós que narravam histórias periodicamente. Infelizmente, hoje em dia, diante de mudanças sociais como a entrada da mulher no mercado de trabalho, o exercício de mais de uma função ao mesmo tempo, a pouca disponibilidade das pessoas, a influência e popularização da mídia, além das tecnologias, parece que existe escassez de contadores de histórias. Esta afirmativa não encontra apoio nas ideias de Machado (2004), que acredita haver ainda muitas pessoas se dedicando à arte de contar histórias que, segundo a autora,

é um fato inegável e curioso, não só no Brasil, mas também em outras partes do mundo. Se por um lado os velhos contadores tradicionais estão desaparecendo, porque nas comunidades rurais a televisão ocupa implacavelmente seu lugar, nos grandes centros urbanos a quantidade de gente que se dedica a essa arte está crescendo. Ninguém mandou, não é uma moda importada; parece que se trata de um sentimento de urgência que faz nascer das cinzas uma ética adormecida, uma solidariedade não mais do que básica, num mundo de cabeça para baixo (MACHADO, 2004, p.31).

No entanto, comparando dados históricos, observa-se que nos dias atuais existem menos avós ou contadores que se interessem pela profissão do que antigamente. Os tempos são outros, o traba- 
lho e a tecnologia não deixam espaço para o contador dos tempos passados que contava as histórias de memória, associando essas histórias a casos que ouviam e ao seu cotidiano, histórias aprendidas com os seus antepassados ou as criadas em cima delas, por meio de outras fantasias, fazendo modificações sem perder a essência principal: o encantamento, o imaginário, o sonho.

Por isso, com esses projetos, objetiva-se resgatar a cultura e a tradição de contar histórias - tanto para crianças quanto para adultos. Mas, há sempre uma dúvida sobre o conceito: "história" ou "estória"? Muitos linguistas, escritores, profissionais e estudantes sempre levantam esta questão quando vão escrever. Entretanto, esta não é uma questão central que influencia na realização de um trabalho com a atividade de "contação de histórias". Mas, entende-se que compreender a diferença pode auxiliar na adoção de uma ou outra e na forma de levar esta atividade aos grupos específicos. De acordo com Ferreira (2008):

História é a narração dos fatos notáveis ocorridos na vida dos povos, em particular, e da humanidade, em geral. Um conjunto de conhecimentos, adquiridos através da tradição e/ou mediante documentos, acerca da evolução do passado da humanidade. Ciência e método que permitem adquiri-los e transmiti-los. Narração de acontecimentos, ações, fatos ou particularidades relativos a um determinado assunto. [...]. Estória é: narrativa de ficção; exposição romanceada de fatos puramente imaginários (distinta da história, que se baseia em documentos ou testemunhos); conto, novela, fábula: estórias de quadrinhos./ Ant. História. (FERREIRA, 2008, p. 454)

Nos projetos aqui relatados, não há diferenciação do conceito: trabalha-se a contação de histórias que trazem os livros infantis, as tradições orais, os diversos tipos de texto que encontram-se na literatura. Ao levar a atividade para fora das salas de aula de graduação e interagir com os grupos comunitários da cidade, entramos no campo da ação extensionista, uma vertente muito valorizada atualmente nas universidades brasileiras, constituindo-se na visão de Franco (2009), uma fonte de produção de conhecimento quando atenta-se às demandas apresentadas pelas pessoas com as quais o trabalho será realizado. É importante ouvi-las na tentativa de incorporar sua visão de mundo, seus interesses e suas preocupações, promovendo trocas mútuas e atenção ao significado de suas ações, assim como reconhecer que há um não saber que só pode ser desvelado na relação que se estabelece entre os interessados. 
Nessa proposta, os professores adquirem conhecimentos e exercitam os que já possuem em sua formação, que foram construídos ao longo de sua prática na educação infantil, aprimorando-se profissionalmente. Dessa forma, articulou-se a extensão, o ensino e a pesquisa, proporcionando não somente aos professores mais uma oportunidade de integrar diferentes áreas de conhecimento, mas também aos estudantes uma experiência rica de relacionar teoria e prática, pesquisar e construir conhecimentos que ultrapassem os limites da universidade e alcancem a comunidade viçosense, numa relação de troca e de reconstrução de saberes.

Associado ao gosto pela narrativa e à priorização das trocas sociais, reconhece-se também, nesses projetos, a importância da literatura para a formação de professores, principalmente para aqueles que atuam na educação infantil. Nesse sentido é preciso que o educador, antes de tudo, encante-se, ou seja, envolva-se na história, de forma a contagiar as crianças, sem perder o fio da meada ou chamar mais atenção para si do que para o conto. Deve expressar sentimentos e emoções, movimentar-se, interagindo com os ouvintes. Essa é uma atividade que deve ser prazerosa para todos, possibilitando às crianças o desenvolvimento da imaginação e da criação.

As atividades possibilitam um novo olhar sobre a riqueza dos contos e os professores também se alimentam de cultura; além disso, eles passam a interagir com mais um objeto de conhecimento: o livro de história infantil, introduzindo-a como uma atividade permanente em suas aulas. Como proposto no Referencial Curricular Nacional para a Educação Infantil (1998), os profissionais têm a possibilidade de narrar histórias com o uso de diferentes recursos didáticos, ao mesmo tempo em que descobrem novas formas de contar a história, criando seus próprios instrumentos e compartilhando experiências.

Contar história é uma atividade que deve fazer parte não somente do currículo da educação infantil, mas também do ensino fundamental; não como uma atividade esporádica, para preencher ou passar o tempo, mas como uma atividade permanente, que deve ser contada todos os dias, para todas as crianças da sala. Deve ser, entre outras, mais uma atividade lúdica para a criança e deve ser desenvolvida de forma coletiva, porém, isso não tem ocorrido, conforme constata-se nas observações de campo.

A arte de contar histórias proporciona à criança possibilidades de fazer diferentes leituras do mundo, podendo criar e imaginar situações que a faça estabelecer relações consigo própria e com o mundo que a cerca. A história proporciona o desenvolvimento da criatividade, possibilita o desenvolvimento da autoestima, da con- 
fiança da criança, o que afeta o seu pleno restabelecimento, como mostram alguns trabalhos que salientam o seu uso terapêutico para favorecer a recuperação de crianças hospitalizadas ou não, conforme Araujo (2009).

Quanto ao conteúdo, as histórias infantis trazem um misto de realidade, ficção, mito e a criança necessita do contato com estes elementos para que se garanta seu desenvolvimento pleno. Ela precisa saber que o lobo mau é uma invenção que está na história, que a Chapeuzinho Vermelho é uma menina inventada, mas que na realidade existem, de fato, lobos e meninas. A forma de trabalhar com estas questões é que tem de ser pensada e assumida criticamente, e a partir de reflexão, baseada em argumentos teóricos fortes. Cunha (2003) defende que

a literatura infanto-juvenil, por sua forma específica de comunicação, mediatizada pelo livro, lidando com o simbólico, com o imaginário pode se constituir em terreno propício à criação de novas formas de relacionamento com a criança. Ao invés de seguir modelos, erigir-se como modelo (CUNHA, 2003, p.29).

Diante das afirmativas de Cunha, o que estamos colocando em cheque é a postura autoritária que adultos adotam perante a criança, oferecendo-lhe aquilo que acham ser o melhor para ela, sem buscar observá-la e apreender suas necessidades, seja pela conversa sincera ou pelas suas manifestações concretas: gestos, atitude de recepção ou não, expressão corporal diante de uma história que está sendo contada. È preciso lembrar que a criança é um ser ativo, que não digere informações apenas, elas as transformam e recriam em função de suas necessidades e experiências. A criança é totalmente capaz de manifestar, de acordo com a idade e suas capacidades aquilo que lhe agrada ou não.

Quanto às cantigas de roda, que eram cantadas para ninar os bebês, ou para brincar na rua, na escola, nos encontros com os amigos e parentes, parecem ter perdido espaço para outras atividades. Fischer (1983), explica que

as coisas antigas, aparentemente há muito esquecidas, são preservadas dentro de nós, elas continuam a agir dentro de nós - frequentemente sem que as percebamos - e de repente vêm a superfície e começam emergir [...]. Em diferentes períodos, dependendo da situação social e das necessidades das classes em ascensão ou em declínio, diversas coisas que permaneciam latentes ou eram dadas como perdidas são trazidas à 
luz do dia e despertam para uma nova vida (FISCHER, 1983, p.26).

Atualmente, no entanto, há muitos programas televisivos e grupos que estão integrando as duas atividades e resgatando-as culturalmente, levando-as para praças, teatros, escolas, etc. Sisto (2005) define o contador como "aquele que junta pessoas para encantar pela palavra. Ele não desapareceu com o tempo, mas sim se multiplicou e tornou-se obrigatório na promoção da leitura e no resgate do lúdico e da fantasia." (SISTO, 2005, p.12). É importante pensar que o contador de histórias deve se preocupar com a questão do lúdico, do contar história com prazer. Deixar quem ouve, ouvir por prazer e sem compromisso de ter que aprender algo. Dessa forma, o ouvinte pode se interessar e se tornar um excelente contador de história, porque passa a ser como um grão de semente que foi plantado, e assim pode se tornar um multiplicador.

A contação de histórias é do tempo em que as brincadeiras eram de esconde-esconde, de bolinha de gude, de peteca, de amarelinha, de bandeirinha, de pique pega. As cantigas de roda eram, por exemplo, atirei o pau no gato, ciranda cirandinha, corre cotia, o passa anel, fui no Itororó, a carrocinha, a rolinha, entre outras. Estas estão praticamente esquecidas e se perdem no tempo. As crianças já não conhecem as letras porque hoje existem as mídias, os computadores, brinquedos eletrônicos e TV, os quais ocupam o tempo das crianças e elas ficam impedidas de aprender e gostar das brincadeiras de roda.

Quanto aos pais, a jornada de trabalho e o consumismo exacerbado os impedem de passar mais tempo com os filhos e transmitir a eles, através da oralidade, os conhecimentos aprendidos de seus antepassados como pais, avós, tios, vizinhos, compadres. Nas experiências de estágio nos últimos anos, foi recorrente a prática de colocar as crianças durante um longo período em frente à TV, sendo que estas poderiam ter desenvolvido atividades mais desafiantes e interessantes, que proporcionassem, de fato, o desenvolvimento nos aspectos físico-motor, social, afetivo, cognitivo e moral. Assistindo TV, a criança se mantém inerte por períodos que ultrapassam sua capacidade de concentração e de permanecer "quieta". Desta forma, visando atender as recomendações contidas no Referencial Curricular Nacional para a Educação Infantil no que se refere às atividades com as crianças, além das atividades de artes, os projetos contemplam também atividades de corpo, som e movimento para dar a estas crianças o direito de exercer o que mais lhes envolve: o movimento dentro de uma perspectiva lúdica.

As formas de exercitar a arte, especialmente na educação formal, 
têm sido trabalhadas em um formato equivocado, que não promovem a liberdade nem a ludicidade. Assim, conforme Cunha (2007), as imagens disponibilizadas cotidianamente, através dos meios de comunicação e das corporações de entretenimento, se tornam as principais referências para que as crianças organizem seus imaginários e construam as imagens, tendo em vista que outros repertórios visuais, como os das artes visuais e de outras produções culturais, não participem frequentemente de suas vidas. Derdyk (1989) alerta que os imaginários infantis estão sendo mediados e formulados pelas diversas produções culturais de forma equivocada.

Cada vez mais a conduta infantil é marcada pelos clichês, pelas citações e imagens emprestadas. "A TV traz o mundo para você”. O imaginário contemporâneo é entregue a domicílio. A criança é submetida a um profundo condicionamento cultural, e é sobre estes conteúdos que a criança vai operar. A ilustração, o desenho animado, a história em quadrinhos, a propaganda, a embalagem são representações que se tornam quase realidades. O elefante desenhado é mais verdadeiro e presente do que o verdadeiro elefante que mora no zoológico, onde a criança raramente vai. Vivemos hoje sob o signo da ficção e da paródia (DERDYK, 1989).

Apesar desta constatação, percebe-se que a contação de histórias está sendo resgatada e a criança que tem a oportunidade de ouvir histórias se sente mais feliz, mais liberta, a criança passa a ter o prazer de parar o que está fazendo para ouvir a história e pedir ao contador que conte outra vez. Dessa maneira é perceptível quando o contador de história se torna um amante, faz com prazer e com alegria.

Bussato (2006), confirmando relato acima, afirma que os contadores da contemporaneidade estão fazendo uso da tecnologia, como a multimídia e a internet, para contar histórias. Essa tecnologia avançada substitui o homem com eficácia, entretanto essa mesma tecnologia não substitui o homem no sentimento, na espontaneidade que acontece na oralidade, no ato de narrar a história. De qualquer forma, ao colocar uma mídia com o objetivo de contar histórias, tem-se a vantagem de contar com um som nítido e alto, pode-se aumentar ou diminuir o volume de acordo com o número de pessoas. Se o lugar é mais amplo, há maior possibilidade das pessoas ouvirem com precisão o que está tocando no aparelho. $\mathrm{O}$ contador está presente sempre que necessário e a história continua igual todas as vezes, e isso é prático, diz a autora.

È importante ressaltar que o contador contemporâneo é, na sua maioria, ator, mestre e até doutor, que está cada dia mais se espe- 
cializando na arte de contar histórias. Muitos contadores vestem-se como algum personagem e fazem uso de fantasias ou bonecos de fantoches, garrafas plásticas, pedaços de algodão, roupas coloridas, dançam, cantam, pulam. E alguns preferem não usar nada, apenas a sua própria roupa e voz. Esses profissionais durante o dia estudam a história e depois de memorizada, repassa duas ou três vezes. As histórias são pequenas, porque falta tempo.

Em meio a toda essa situação, o contador ainda vive a frustração de não ter público suficiente para a realização do seu espetáculo. Esse tipo de contador procura normalmente os locais onde as crianças têm uma gama diversa de atividades de diversão como, por exemplo, os parques, cinema, lojas de jogos eletrônicos. Em época de Natal, há concorrência com as mais lindas decorações, Papai Noel e suas renas dominam como personagens, e assim torna-se maior o número de crianças e maiores as possibilidades de atingir um público amplo (BUSSẢTO, 2006)

Quanto ao aspecto afetivo, Sunderland (2005) afirma que as crianças não sabem lidar com os sentimentos: a raiva, a tristeza, os medos, a solidão. Elas não sabem o que fazer e como fazer para resolver os seus conflitos internos e externos. Às vezes, elas se manifestam dizendo que estão chateadas ou tristes. Os adultos procuram resolver a situação de uma forma muito complexa para o nível de desenvolvimento e a capacidade de compreensão da criança que, muitas vezes, ainda não consegue compreender a linguagem do adulto. Para entrar no mundo da criança é preciso usar de metáforas e as histórias podem ser o caminho, porque, ao ouvi-las, a criança sai do seu mundo real e entra num mundo do faz-de-conta, de fantasias. Ela consegue penetrar num mundo onde todas as coisas são possíveis. Ao narrar uma história, imediatamente o ouvinte ou mesmo o leitor afasta-se do seu mundo real. È esse distanciamento que proporciona a liberação de sentimentos e a externalização de seus medos, alegrias, desejos etc.

Bussato (2006) completa que o conto oral é mais um divertimento para a criança, esses contos têm o poder de acalmar, de ninar, e faz a criança se lembrar do berço e da voz da mãe, acalentando-a e acalmando-a até pegar no sono. A leitura interativa de livros de histórias infantis para crianças favorece o desenvolvimento do seu vocabulário e da capacidade de compreensão da mesma. É o que confirma o trabalho de Oliveira (1998), no qual a autora relata o desenvolvimento de leitura de histórias com crianças de baixo nível socioeconômico.

Para desenvolver essa estratégia de envolver a criança no contexto da história, é preciso que o professor reflita sobre a leitura 
e o faça com prazer. Nessa mesma direção, em uma reflexão sobre leitura, prazer e saber, Sousa diz que

o prazer ganha forças de afirmação de direitos, num sistema escolar que perpetuou a leitura como dever, obrigação, custo. Isso significa que as instituições de ensino necessitam ajustar seus valores e funções aos conceitos de imaginário, imprimindo uma orientação pedagógica recuperadora do sentimento da presença do corpo, do domínio corporal...(SOUZA, 1998, p.15).

Bussatto (2006) completa que devemos pensar a contação de histórias como um passaporte para o imaginário que oferece um vasto campo de possibilidades, abrindo os seres humanos para sistemas participativos, plurais, sensíveis e passíveis de outras lógicas. Para a autora, "a partir do imaginário e suas manifestações, é possível retornar à matéria humana e ressensibilizar o mundo e o ser humano e isso pode também ocorrer pelo aconchego oferecido pelas histórias e pelo espírito de amorosidade que flui numa narrativa oral realizada com prazer".

Voltando às brincadeiras de roda, estudos mostram que estas têm um lugar privilegiado na cultura infantil porque revela ampla inclusão da criança com as linguagens oral, corporal, musical, gestual e muitas possibilidades de criação de novos movimentos de aprendizagem. Os projetos de contação de histórias que fazem um trabalho de inter-relação entre as histórias e as cantigas de roda trazem um grande benefício para o desenvolvimento integral das crianças. É nessa descontração lúdica que a criança se movimenta, exercita, alonga, aprende as letras das cantigas, se expressa e interage socialmente. A brincadeira de roda e a contação de história tornam-se fontes integradas de pesquisa nos dias atuais. Remete o sujeito ao passado e, ao mesmo tempo, se faz presente na vida das crianças.

Observa-se que brincadeiras de roda e contação de histórias estão associadas e precisam ser mais valorizadas como práticas socioculturais. Portanto, estudos revelam que há um rico universo das rodas cantadas, das brincadeiras infantis e das contações de histórias que são relevantes para o desenvolvimento da criança. Esse universo deve ser estendido para a dimensão lúdica nas práticas educativas na educação infantil, já que o mesmo possibilita oportunidades para um desenvolvimento mais amplo da criança. Apesar da carga moral carregada em diversas histórias, como é o caso das fábulas e de contos de fada, nem todas se constituem desta característica. Há uma gama de opções de livros no mercado e nas tradições. No projeto apresentado neste artigo, optou-se por histó- 
rias que não revelem esta preocupação, ou seja, histórias de cunho moral marcadamente evidenciado no texto. Caso seja constatado que há uma carga moral implícita ou explícita, após a contação da história, faz-se uma discussão com as crianças, levando-as a pensar nas mensagens transmitidas pela história e a propor um novo enredo para a mesma.

\section{PROCEDIMENTOS METODOLÓGICOS}

Para a implementação desse projeto, foi constituída uma equipe de professores e estudantes do curso de graduação em Educação Infantil da Universidade Federal de Viçosa. Os estudantes puderam relacionar teoria e prática, na medida em que estiveram participando do planejamento e do desenvolvimento das atividades, de discussões e reflexões, que ocorreram em reuniões periódicas, além da produção de material didático para o desenvolvimento das aulas que certamente contribuíram para o seu desenvolvimento pessoal e profissional.

Para levantar as demandas dos professores quanto às necessidades de treinamento, foi realizada uma entrevista individual, utilizando a técnica da conversa clínica, que teve por objetivo ouvir o profissional e estabelecer, junto ao mesmo, as ações para seu treinamento.

Após a análise das respostas, elaborou-se o plano da oficina de forma que atendesse ao que fora demandado pela maioria do grupo. No ano de 2012, o projeto "A Imaginação e o Lúdico: A Contação de Histórias Infantis" promoveu a oficina de contação, com a participação de professores que atuavam na educação infantil, na rede pública do município de Viçosa - MG. A oficina foi oferecida aos sábados para atender às necessidades e aos interesses dos participantes, por meio de aulas teóricas e práticas, em módulos presenciais e não presenciais, com uma carga horária de 36 horas.

Durante o primeiro módulo, a equipe ministrou aulas teóricas e práticas sobre a importância de se contar histórias e seus recursos. Houve uma seleção e confecção de instrumentos para contação de histórias por parte dos profissionais participantes, com apoio da equipe do projeto. No segundo módulo, os profissionais contaram as histórias que confeccionaram em sua própria instituição, com acompanhamento da equipe do projeto. No terceiro módulo, aconteceu a contação de histórias na Praça Silviano Brandão, onde os participantes do curso contaram as histórias confeccionadas no decorrer do mesmo, juntamente com a equipe do projeto.

O material escolhido para confecção das histórias é o que seria descartado. Essa é uma preocupação do grupo e dos profissionais 
envolvidos, que escolhem retalhos de papel, de tecidos, papelão, sucatas, garrafas PET, caixas de sapato, meias etc... Roupas em desuso podem se tornar histórias de fichas, de flanelógrafo, fantoches etc, trazendo grande entusiasmo para os participantes que percebem o valor de suas obras, quando estas são apreciadas pelas crianças e pelos adultos (pais, avós e demais pessoas da comunidade).

As atividades do projeto não se limitam aos cursos. São realizadas contações de histórias infantis uma vez ao mês, aos sábados, na Praça Silviano Brandão. Durante estas contações, além de várias histórias com uso de fantoches, fichas, livros e TV gravura, também há realização de sorteio de livros para que as crianças possam ter este instrumento em casa e criar o hábito de ler ou, se ainda não souber ler, seus pais ou responsáveis o façam por ela e para ela. Além disso, são realizadas apresentações teatrais e musicais.

Uma outra atividade é a participação de contadores de histórias de Viçosa e região na Praça Silviano Brandão, atendendo a um dos objetivos inovadores do projeto de forma a levar à comunidade acadêmica (estudantes, técnicos e professores envolvidos no projeto) e viçosense, novas formas e maneiras de contar histórias, divulgando a cultura e o folclore da região, proporcionando também uma "troca de saberes". A atividade de contação de histórias desenvolvida na praça, por meio dos professores e a equipe de estudantes, é amplamente divulgada nos meios de comunicação.

Cria-se um cenário simples: uma cortina colocada entre duas árvores, uma almofada e uma lona cobrindo o chão. Nesse espaço, a imaginação e a criatividade invadem as mentes de crianças e pessoas de idades variadas. O poder da palavra, o narrar e o contato olho no olho leva a esse público variado as aventuras que podem ser vivenciadas em cada história.

O público é itinerante, o que torna quase impossível contabilizar quantas pessoas passam pela praça e param para ouvir uma história: crianças, adolescentes, jovens, adultos e idosos. Todos ouvem as histórias contadas como simples narrativas, com fantoches de luvas, livros, rádio-história, histórias em fichas e também assistem às peças teatrais infantis adaptadas ou criadas pela equipe de bolsistas e voluntários. As crianças entram num clima de puro encantamento e magia, os olhos brilham a cada palavra e ao final da história percebe-se que se interessam muito. Ao final de cada história, elas podem manusear os materiais e têm oportunidade de recontar a história do seu jeito, narrando o que mais gostou, recriando cenários, fatos e personagens.

Entre uma história e outra, há um intervalo para a brincadeira 
de roda, onde as crianças se exercitam e aprendem a tradição relacionada a atividades de música e dança, com suas possíveis coreografias. As músicas são alegres e contagiam as crianças, ao mesmo tempo em que também contam histórias de cada região. Enquanto brincam de roda de mãos dadas, as crianças se socializam e conhecem a cultura tanto local quanto de outras regiões. A música "Eu vou andar de trem" já virou tradição e, ao ouvirem o CD com o som do trem, as crianças já se aproximam, participam da dança na praça, sentando-se logo em seguida na lona colocada no chão da praça porque sabem que ali é o cantinho reservado para elas ouvirem as histórias e brincarem de roda.

Os resultados são observados imediatamente e a longo prazo. Percebe-se que, muitas vezes, crianças e adultos retornam à praça para ouvir histórias e participar das atividades. Trabalhos de pesquisa como os de Oliveira (1998); Ferreira (2005); Marquezan (2005) reafirmam a importância de ouvir histórias para o desenvolvimento e aprendizagem da criança, principalmente no aspecto cognitivo, no campo da linguagem oral e escrita e nos aspectos afetivos e socioculturais, tornando-se, também, um instrumento importante para facilitar as interações entre as crianças durante a contação da história, no reconto da história (no qual expressam-se dentro de suas capacidades e exercitam a capacidade criativa, modificando textos, personagens, cenários etc) e nos comentários, desenvolvendo a fala, a capacidade de expressar-se e de ouvir o outro.

\section{RESULTADOS E DISCUSSÃO}

Ao trabalhar com confecção de material didático para a instrumentalização dos professores no que diz respeito à arte de contar histórias, faz com que se reutilizem materiais que normalmente seriam descartados pela população da cidade de Viçosa. Isso promove a melhoria da educação ambiental e uma formação consciente do cidadão, bem como se contribui para a construção de uma nação mais justa. O combate à geração de lixo em excesso é uma responsabilidade de todos e como afirma Maria (2006), a iniciativa de muitos profissionais, envolvendo nos projetos crianças, pais e a comunidade, em defesa não somente da educação infantil, mas também da educação ambiental, tem sido uma preocupação constante.

Com relação à ação extensionista, Bartnik e Silva (2009) afirmam que muitas mudanças ocorreram nas universidades, iniciando um processo de expansão de suas atividades para além do ensino e da pesquisa. A extensão universitária no Brasil data do começo do século XX, mas esta é influenciada por duas correntes: européia, por meio dos cursos de Extensão, resultantes dos esforços autônomo 
dos intelectuais, com objetivo de aproximar-se da população; e a norte-americana, voltada para o desenvolvimento das comunidades, caracterizada pela prestação de serviços.

No entanto, uma nova proposta passa a ser visualizada a partir de estudos dos efeitos desta ação, e as universidades mudam seu foco para as necessidades percebidas pelas comunidades atendidas. Desta forma, as atuais propostas de extensão partem dos anseios que as próprias pessoas e grupos comunitários demonstram e, a partir desta constatação, a extensão procura atender a demandas que estes grupos apresentam. Em função disso, decorre a necessidade de projetos que visem associar as ações em um processo de formação extra-curricular que articula a pesquisa e o ensino, visando o enriquecimento de processos pedagógicos, dentro e fora da academia, focando a educação e a geração de aprendizado coletivo construído por meio das práticas extensionistas.

Essa foi uma inquietação do grupo e dos profissionais envolvidos no projeto: adotar o uso de materiais recicláveis, o que contribui para amenizar o descarte no ambiente, bem como seu desgaste. Outro resultado alcançado foi o grande número de crianças atendidas nas instituições de educação infantil, por meio da contação de histórias, além daquelas que participam dessa atividade na praça. Um excelente resultado foi a contação de histórias na praça tornar-se uma atividade independente do projeto, passando a ocorrer uma vez ao mês e não somente durante o desenvolvimento do módulo não presencial, como estava previsto no projeto original.

As contações de história em uma praça pública têm mostrado como a participação da universidade em outros espaços fora do campo acadêmico podem contribuir para a disseminação da cultura e do hábito de ler, fundamentais para a formação do bom leitor, que conforme coloca Abramovick (1995), é importante para o desenvolvimento de qualquer criança ouvir muitas, muitas histórias. Escutar as histórias é o início da aprendizagem para ser um leitor, o que contribui para um caminho absolutamente infinito de descoberta e de compreensão do mundo. Complementando isto, neste projeto compreende-se a criança como um sujeito que já é, e não que virá a ser, oportunizando a ela o contato direto e no tempo presente a uma forma de estímulo da imaginação, da criatividade, da possibilidade de resolver conflitos, dentre outras vantagens.

Observa-se nas atividades de contação como as crianças se identificam com determinados personagens por meio de seus relatos de vida, associando situações vivenciadas no dia a dia ou fazendo referências a situações relatadas por outras pessoas. Uma questão muito importante a ser levantada é o planejamento que é realizado 
para que as atividades aconteçam. A utilização de diversos recursos para contar histórias gera uma expectativa nos ouvintes para o "que vem depois".

\section{Afirmam Costa e Valdez:}

Ao escolher a leitura é preciso pensar na forma de contá-la [...]. Mesmo que a história seja contada pela milésima vez. Além de usar o livro, mostrando ou não as imagens, de contar a história decorada, de usar fantoches, de usar o avental e de apresentar as histórias, é possível recorrer a outras formas interessantes e atrativas. Isso inclui a preparação da história e do ambiente (COSTA \& VALDEZ, 2007, p.174).

Planejar um projeto que acontece em uma praça pública ainda tem outras implicações: o público é itinerante e diversificado, como por exemplo, bebês acompanhados de seus pais ou responsáveis e idosos com as mais variadas formações, histórias de vida etc. Desta forma, a cada atividade proposta, é necessário que a equipe do projeto se reúna, semanalmente, para definição das estratégias para atendimento deste público. Estipula-se que uma média de 200 crianças passem pela praça, por dia, circulando nos vários momentos em que as atividades acontecem. Além destas, familiares ou cuidadores também necessitam permanecer no espaço, uma vez que não há possibilidade do grupo responsabilizar-se pelo cuidado delas. Esta situação faz com que muitas famílias aprendam, ao ouvir histórias com seus filhos, a importância da mesma na vida da criança. No relato de uma mãe, pode-se perceber o quanto esta atividade é importante:

Trago meus dois filhos sempre que posso. Quando não é possível, peço à babá ou ao pai e até mesmo minhas vizinhas...não dá pra perder o dia de contação na praça. Os meninos sempre perguntam que dia vai ter e reclamam quando falo que não tem naquele sábado! (depoimento de uma mãe durante a contação na praça, em 2012.)

Quanto aos profissionais da educação, seja educação infantil ou mesmo de outros níveis de ensino, eles param e perguntam se o grupo pode atender a algum evento na escola. A equipe sempre analisa a possibilidade, mas reforça que o próprio professor pode implantar no seu planejamento, atividades de contação de histórias tanto para a promoção da ludicidade e da arte, como utilizá-la como recurso pedagógico. Muitos profissionais de educação infantil, ao presenciarem as atividades na praça, procuram a equipe para saber 
sobre as técnicas que são utilizadas na confecção destas novas possibilidades para poderem usá-las em seu cotidiano. Amplia-se, desta forma, a visão que os profissionais têm de que a história pode ser contada mesmo quando não se têm livros, utilizando recursos que seriam descartados e conferindo-lhes nova utilidade. Trabalha-se, nesta dinâmica, a questão ambiental, promovendo o reaproveitamento de materiais e diminuindo, mesmo que em pequena escala, o descarte de materiais na natureza.

A criatividade também é estimulada, pois o que era uma caixa vira um cenário inteiro, ou uma garrafa plástica se transforma em uma personagem de um conto de fada, uma linha e um botão poderão compor os acessórios de um carro, e assim por diante.

A participação das pessoas nas contações na praça e mesmo as que são realizadas nas escolas da cidade e da região, indicam que a história é um excelente recurso para o trabalho lúdico voltado para a criança e que pode servir como meio para várias atividades como as de linguagem oral e escrita, de matemática, ciências, conhecimento de mundo, corpo e movimento, musicalização, bem como para o trabalho com temas transversais e projetos. Contar histórias é uma arte que contribui com todas as outras, podendo ser atrelada a atividades de música, corpo e movimento, pintura, escultura, recorte e colagem, desenho.

A oralidade, tão exigida neste tipo de atividade, permite a formação simbólica do indivíduo, possibilitando-lhe ver o mundo além do que é visível, através daquilo que é imaginável. Este ganho reflete também no processo de alfabetização do sujeito, que parte de uma forma lúdica sem a necessidade de decorar sequencias de letras, de palavras e frases. Por meio do contato com a história, a alfabetização ocorre de forma mais dinâmica e mais leve, quebrando a monotonia de atividades dirigidas e com finalidades rígidas de se obter resultados.

Com a implementação deste projeto, está sendo possível levar a arte e a cultura de contar histórias, promover o estabelecimento do hábito de leituras saudáveis que gerem a diversão, a imaginação, a criatividade dos grupos atendidos, minimizando e diminuindo a estatística de baixo nível de leitura mostrada em trabalhos científicos diversos.

Considera-se que o projeto tenha impactos sociais de incluir a arte e a cultura lúdica na vida do público atendido, valorizando as produções individuais e coletivas, ampliando o acesso das pessoas às diferentes formas de contação de histórias, tornando uma prática cotidiana na vida das pessoas, além de estimular crianças, jovens 
e adultos a desenvolver o gosto pela leitura e pelo teatro e fazer destas atividades uma forma lúdica de lazer, promovendo o contato familiar e a interação entre os indivíduos.

A capacitação de professores e gestores da educação infantil e ensino fundamental tem possibilitado que se conscientizem da necessidade de inclusão da contação de histórias e da apresentação de teatro como atividades diárias nas escolas e meio para desenvolvimento integral da criança. A democratização de conhecimentos e do acesso ao livro e às diferentes formas de contação de histórias e de peças teatrais vem ocorrendo juntamente com a ampliação e a divulgação de conhecimento a respeito das ações propostas no que se refere à literatura, às cantigas de roda e ao teatro.

As produções obtidas por meio do curso têm gerado novas ideias para os professores da educação infantil, que têm obtido bons resultados no trabalho de intervenção junto às crianças e ampliado as possibilidades quanto aos recursos: encontra-se nestas escolas atendidas nos projetos já um número maior de histórias adaptadas e confeccionadas com recursos variados e em diferentes modalidades: TV gravura, flanelógrafo, fantoches, varais de histórias, rádio-história (que é uma criação nossa), dentre outras. Isto tudo tem implicado em melhoria da qualidade da formação profissional e aparecendo no desenvolvimento das crianças atendidas.

\section{CONSIDERAÇÕES FINAIS}

Considerando os resultados alcançados até o momento, percebe-se que os objetivos desse projeto são alcançados gradativamente, à medida que professores e a comunidade se conscientizam da importância desse tipo de atividade não somente para o desenvolvimento e a aprendizagem das crianças, mas por despertar nelas o prazer de ouvir histórias, contadas com o uso de diferentes recursos didáticos como fantoches, flanelógrafo, TV gravuras etc. e principalmente, encantar os educadores, tocando sua sensibilidade e desenvolvendo neles o gosto pela narrativa.

As atividades da oficina têm grande repercussão na comunidade, tanto no oferecimento da oficina para os professores de educação infantil, quanto das atividades de contação de histórias na praça. $\mathrm{O}$ projeto está sendo bem aceito pela comunidade, contribuindo para a melhoria da educação no município. A equipe tem recebido convites para outros eventos. A cada evento de contação de histórias na praça, aumenta a participação da comunidade, incluindo crianças, famílias, entre outros. Os professores participantes demonstram boa aceitação à oficina e interesse em continuar as atividades, contribuindo assim 
para tornar a contação de histórias infantis uma atividade permanente, incluindo-a no currículo da educação infantil. Esse é um processo que depende também do incentivo dos dirigentes municipais em investir na literatura infantil, adquirindo livros para as instituições.

Os impactos alcançados com esse projeto, especificamente, se darão ao longo do tempo, pois envolvem transformações sociais e culturais. No entanto, de acordo com as discussões e reflexões desenvolvidas na oficina, percebe-se grande possibilidade de inserção da contação de histórias infantis no currículo da educação infantil em cada uma das instituições representadas, mas como uma atividade permanente e não desenvolvida esporadicamente, apenas para preencher ou passar o tempo.

Nota-se a contribuição para o desenvolvimento da cidadania, por meio da contação de histórias infantis nas instituições e na praça, envolvendo a comunidade escolar e a comunidade viçosense, sendo essa segunda representada por crianças, pais, avós, entre outros, melhorando a educação e a qualidade de vida da população. Promove-se a integração da família, interação entre professores, estudantes e a comunidade, possibilitando uma experiência rica de diálogos e trocas efetivas de experiências, o que poderá repercutir, de forma positiva, na educação das crianças.

As estudantes envolvidas no projeto têm a oportunidade de relacionar teoria e prática, na medida em que participam do planejamento e do desenvolvimento das atividades, de discussões e reflexões que certamente contribuíram para o desenvolvimento pessoal e profissional. Além disso, professores e estudantes podem desenvolver instrumentos metodológicos buscando alternativas de transformação da realidade que contribuem para a construção de conhecimentos inerentes à prática de contação de histórias e sua própria formação profissional, ampliando assim o alcance do projeto para a comunidade escolar e viçosense.

O projeto leva à comunidade a oportunidade de contato com diferentes formas de contação de histórias, utilizando recursos de fácil acesso e baixo custo, reaproveitando materiais que seriam descartados, contribuindo assim, com a preservação do meio ambiente. Os estudantes envolvidos ampliam sua visão de extensão a partir das atividades propostas pelo projeto, estabelecendo uma relação entre universidade e sociedade, de forma sistematizada, apreendendo sobre o meio social com o qual ela se relaciona na realidade nas três vertentes: ensino, pesquisa e extensão. Diante das experiências acumuladas, tornam-se críticos da própria prática e podem, a partir da sua auto-avaliação rever processos, atitudes, valores e repensar suas práticas educacionais. Exercitam e 
ampliam os conhecimentos teóricos aprendidos no campo acadêmico e renovando-os por meio de trocas sociais que estabelecem nas várias atividades do projeto. Tornam-se responsáveis e ativos, pois as ações propostas exigem destes, dedicação e compromisso para efetivação de suas atividades. Quanto ao público que ouve e participa da contação de histórias na praça, estes têm a possibilidade de conhecer e se divertir com diferentes formas de contação de histórias. O projeto oferece uma opção a mais de lazer para a população de viçosa e região, além das atividades a que somos convidadas no decorrer do ano em diferentes instituições sociais, para eventos diversos. Os professores que participam das oficinas têm a oportunidade de melhorar sua prática pedagógica, ampliando as possibilidades de trabalho com a literatura infantil nas escolas e de oportunizar às crianças outras formas de aprendizagem, tendo o lúdico como a base de seu trabalho, tornando mais prazerosa a permanência na escola.

Mas ainda não acabou. Existem inquietações que necessitam ser respondidas: os cursos de formação de professores estão preocupados com a qualidade dos profissionais que formam? Os profissionais que já estão no mercado, preocupam-se com sua qualificação e procuram oportunidades para aprender mais sobre os conteúdos que trabalham? A criança é vista como um ser em desenvolvimento, que possui potencialidades e merece respeito ou ainda é vista como aquele que vai ser? Decorre desta visão um trabalho voltado para o desenvolvimento de sua autonomia ou ainda há o trabalho para seu "futuro", menosprezando-se seu potencial? Por fim, que visão de história e, principalmente, de sua importância no cotidiano escolar é adotada e como direciona a prática docente na educação infantil?

Em nosso trabalho ainda nos deparamos com a resistência de alguns profissionais em adotar uma nova postura, uma nova visão de criança e de educação que emperra a adoção de meios mais eficientes de educação de crianças pequenas. Esta situação mostra como as políticas publicas para a formação dos profissionais e para o atendimento às crianças pequenas ainda não alcançaram o patamar ideal que se almeja para melhoria da qualidade de vida desses grupos. 


\section{REFERÊNCIAS BIBLIOGRÁFICAS}

ABRAMOVICH, F. Literatura Infantil: gostosuras e bobices. São Paulo, Scipione, 1995.

ARAUJO, A.M.C. et al. A arte de contar histórias com o livro de folhas soltas: uma experiência junto a crianças em leitos hospitalares. IX Congresso Nacional de Educação - EDUCERE.26 a 29/10/2009.

AURÉLIO, B.H.F. Minidicionário da língua portuguesa. Curitiba: Ed. Positivo, 2008.

BARTNIK, F.M.P.; SILVA, I.M. da. Avaliação da ação extensionista em universidades católicas e comunitárias. São Paulo, v.14, n.2, p.267-290, jul. 2009.

BRASIL, Ministério da Educação e Desporto. Referencial curricular nacional para a Educação Infantil. Secretaria de Educação Fundamental. Brasília: MEC/SEF, 1998.

BUSSATTO, C. Contar e encantar: pequenos segredos da narrativa. Petrópolis: Vozes, 2003.

BUSSATTO, C. A arte de contar histórias no século XXI: tradição e ciberespaço. Petrópolis: Vozes, 2006.

COSTA, P.L.; VALDEZ, D. Ouvir e viver história na Educação Infantil: um direito da criança. São Paulo: Alínea, 2007.

CUNHA, M.A.A. Literatura infantil: teoria e prática. São Paulo: Ática, 2003.

CUNHA, VIEIRA, S.R. Como vai a Arte na Educação Infantil? Revista de Educação CEAP. Salvador, v.56, p.4-12, 2007.

DERDYK, E. Formas de pensar o desenho: desenvolvimento do grafismo infantil. São Paulo: Scipione, 1989.

FRANCO, V.C. O idoso e seus cuidadores: ação extensionista produzindo conhecimento. IV Seminário de Extensão Universitária. 2009.

FERREIRA, A.B.H. Mini dicionario Aurélio da Língua Portuguesa, $7^{\mathrm{a}}$ ed. Curitiba: Positivo, 2008.

MACHADO, R.A. Fundamentos teóricos-poéticos da arte de contar histórias. São Paulo: DCL, 2004.

MARQUEZAN, F.F.; CORRÊA, M.L. A infância e sua educação: olhares através da história. In: ANAIS VI Congresso Internacional de Educação Popular e XVI Seminário Internacional de Educação Popular, 2005, Santa Maria/RS.

MARIA, K.C.O. Como e por que ler os clássicos universais desde cedo. Rio de Janeiro: Objetiva, 2002.

MEIRELES, C. Problemas da Literatura Infantil. $3^{\text {a }}$ ed. Rio de Janeiro: Nova Fronteira, 1984.

OLIVEIRA, M.J. Um estudo de intervenção de leitura de histórias com crianças provenientes de famílias de baixo nível socioeconômico. Belo Horizonte: FAFICH, 1998 (Dissertação de mestrado). 
SISTO, C. Textos e pretextos sobre a arte de contar histórias. Rio de Janeiro: Argos, 2005.

TAHAN, M. A arte de ler e contar história. Rio de Janeiro: Conquista, 1966.

SILVA, M.C.; MARTINS, M.R. Experiências de leitura no contexto escolar. Brasília: Ministério da Educação, Secretaria de Educação Básica, 2010. (Coleção Explorando o Ensino; v.20).

SOUZA, L.O. et al. A contação de histórias como estratégia pedagógica na educação infantil e ensino fundamental. Revista Educere, v.6, n.12, p.235-249, jul./ dez. 2011.

SUNDERLAND, M. O Valor terapêutico de contar histórias. São Paulo: Cultrix, 2005. 